\title{
Elevated serum vascular endothelial growth factor is associated with visceral fat accumulation in human obese subjects
}

\author{
S. Miyazawa-Hoshimoto ${ }^{1}$, K. Takahashi ${ }^{1}$, H. Bujo ${ }^{2}$, N. Hashimoto ${ }^{1,3}$, Y. Saito ${ }^{1}$ \\ ${ }^{1}$ Department of Clinical Cell Biology, Graduate School of Medicine, Chiba University, Chuo-ku, Japan \\ ${ }^{2}$ Department of Genome Research and Clinical Application, Graduate School of Medicine, Chiba University, Chuo-ku, Japan \\ ${ }^{3}$ Division of Applied Translational Research, Graduate School of Medicine, Chiba University, Chuo-ku, Japan
}

\section{Abstract}

Aims/hypothesis. Adipose tissue expresses some bioactive molecules, which may be involved in the development of obesity-associated metabolic disorders and cardiovascular diseases. Vascular endothelial growth factor (VEGF) an important angiogenic factor is implicated in normal and pathological vessel formation. The aim of this study is to investigate clinically the association between blood serum VEGF concentrations and body fat accumulation as well as distribution. The study also aims to show the effect of serum VEGF protein on gene expression of transcriptional factor E26 transformation-specific-1 (Ets-1) and matrix metalloproteinase (MMP)-3.

Methods. Serum VEGF concentrations were measured in 38 overweight or obese subjects. Fat distribution in the abdominal subcutaneous as well as visceral fat areas was assessed by computed tomography scans at umbilical level. Furthermore, the changes of serum VEGF concentrations following body weight reduction therapy were analyzed in eight subjects recruited from the original pool of subjects. Semi-purified circulating VEGF proteins were obtained by heparin-sepharose and its biological activities were shown to alter gene expressions in human aortic endothelial cells. Results. Serum VEGF concentrations were positively correlated with BMI $(\mathrm{r}=0.433, p=0.007)$ and visceral fat area $(\mathrm{r}=0.488, p=0.002)$. Stepwise regression analysis showed the visceral fat area as the most important determinant factor for VEGF circulating levels. Following body weight reduction therapy, VEGF concentrations as well as visceral fat area were decreased. The serum semi-purified VEGF protein enhanced expressions of Ets-1 and MMP-3 in human aortic endothelial cells.

Conclusion/interpretation. Increased serum VEGF concentrations associated with visceral fat accumulation could influence vascular endothelial function. [Diabetologia (2003) 46:1483-1488]

Keywords Adipose tissue, vascular endothelial growth factor, body fat distribution, diet therapy, computed tomography.
Received: 12 December 2002 / Revised: 3 March 2003

Published online: 8 October 2003

(C) Springer-Verlag 2003

Corresponding author: Dr. K. Takahashi, Department of Clinical Cell Biology, Graduate School of Medicine, Chiba University, 1-8-1 Inohana, Chuo-ku, Chiba 260-0856, Japan

E-mail: kazuot@intmed02.m.chiba-u.ac.jp

Abbreviations: PAI-1, plasminogen activator inhibitor-1; IL-6, interleukin-6; VEGF, vascular endothelial growth factor; HAEC, human aortic endothelial cells; FBS, fetal bovine serum; MMP-3, matrix metalloproteinase-3; ETS-1, E26 transformation-specific-1; HOMA, homeostasis model assessment for insulin resistance.
Adipose tissue expresses and releases various secretary molecules, such as leptin $[1,2]$, TNF- $\alpha$ [3], plasminogen activator inhibitor-1 (PAI-1) [4], and interleukin-6 (IL-6) [5]. These molecules may have a potential role in the development of metabolic disorders and cardiovascular diseases resulting from obesity. Blood serum concentration of these molecules has been shown to be directly related to the degree of obesity in human subjects, suggesting that these molecules could be released by adipocytes. Furthermore, weight loss is associated with decreased expression of these molecules in adipose tissues $[6,7,8,9,10]$. The 
latter decrease in gene expression is paralleled by a fall in leptin as well as TNF- $\alpha$ blood serum levels [11, $12,13]$.

Since the 1980's, many researchers have reported that abdominal fat accumulation, evaluated by anthropometric measurements, is a risk factor for the development of obesity-associated metabolic disorders as well as vascular diseases $[14,15]$. Development of elaborate techniques such as computed tomography and ultrasound sonograhy that can produce an accurate measure of abdominal fat distribution revealed that intra-abdominal fat is more closely related to these disorders than an increase in absolute fat volume $[16,17]$. The accumulation of intra-abdominal fat could particularly form a basis of multiple risk factor syndromes through insulin resistance [18]. Studies have revealed that regional differences in production of cytokines between subcutaneous and visceral fat tissues might contribute to the pathological significance of visceral fat accumulation that accompanies insulin resistance $[10,18]$. Previously, we reported that the implantation of adipocytes into the subcutaneous or visceral fat area of athymic mice results in an increased concentration of serum TNF- $\alpha$ and insulin resistance by the adipose cells in the visceral area, but not in the subcutaneous area [19].

Vascular endothelial growth factor (VEGF) is an important angiogenic factor reported to induce migration and proliferation of endothelial cells, enhance vascular permeability, and modulate thrombogenicity [20]. VEGF is therefore implicated in normal blood vessel development as well as in vascular pathologies. The pathogenic neovascularization plays a major role in the development of atherosclerosis, tumour growth, rheumatoid arthritis and various retinopathies. VEGF mRNA expression has been identified in a variety of cell types including endothelial, epithelial and mesenchymal. VEGF mRNA was also found in 3T3-F442A cells, established pre-adipocyte cell lines where it induces adipocyte differentiation [21]. A recent study showed that, relative to controls asymptomatic for arteriosclerosis, circulating VEGF levels were increased in the patients with coronary artery [22].

In this study, we investigated the effect of visceral as well as subcutaneous fat accumulation on serum VEGF concentrations in human subjects. In addition, we examined the biological activity of circulating VEGF to enhance the gene expressions of matrix metalloproteinase-3 (MMP-3) and transcriptional factor E26 transformation-specific-1 (ETS-1). The endothelial expressions of both molecules have been reported to be induced by VEGF [23].

\section{Materials and methods}

Experimental subjects. We studied 38 overweight or obese subjects (10 male and 28 female). All subjects gave informed consent to participate in this study. All anthropometric measurements were taken with the participant wearing light clothes and no shoes. BMI was calculated as weight in kilograms divided by the square of the height in metres metres. Exclusion criteria consisted of diabetes mellitus and sleep apnea syndrome as both disorders are known to raise circulating VEGF concentrations. All participants were defined as non diabetic according to the recent criteria of the WHO for fasting $(<7.0 \mathrm{mmol} / \mathrm{l})$ and post-glucose load level $(<11.1 \mathrm{mmol} / \mathrm{l})$. Furthermore, all subjects were diagnosed as asymptomatic for sleep apnea syndrome using polysomnography. From the original pool of 38 subjects, 8 participants were recruited for weight-loss treatment. The latter subjects were hospitalized and treated with a multidisciplinary approach consisting of diet, exercise, behavioural and nutritional counselling. The mean daily caloric intake was $1200 \mathrm{kcal}$, ranging from 1000 to $1500 \mathrm{kcal}$. Following 2 weeks treatment, all patients witnessed a loss of body weight ranging from 4 to $6 \mathrm{~kg}$.

Measurement of serum immunoreactive VEGF. A fasting venous blood sample was collected. Following centrifugation at $4^{\circ} \mathrm{C}$ the serum fraction was collected. VEGF levels in the serum were measured with the ELISA system (R\&D Systems, Minneapolis, Minn., USA).

Estimation of body fat distribution. According to previously described methodology, computed tomography scans at umbilical level were carried out to calculate abdominal subcutaneous and visceral fat [24].

Homeostais model assessment for insulin resistance (HOMA) index. HOMA index was calculated with the formula: fasting plasma glucose $(\mathrm{mmol} / \mathrm{l}) \times$ fasting insulin $(\mu \mathrm{U} / \mathrm{ml}) / 22.5$, as described previously [25]. HOMA index has been reported to be a metabolic marker for hyperinsulinaemia or insulin resistance $[26,27]$.

Partial purification of VEGF from serum. All the procedures were carried out at $4^{\circ} \mathrm{C}$. The serum of an obese subject $(12 \mathrm{ml})$ was applied into HiTrap Heparin HP column (1 ml of bed volume) (Amersham-Pharmacia Biotech, Uppsala, Sweden) and equilibrated with natural saline. After the column was washed with $10 \mathrm{ml}$ of natural saline, elution was carried out done with $3 \mathrm{ml}$ of $1 \mathrm{~mol} \mathrm{NaCl}$ solution. The elution fraction was dialysis against natural saline and stored at $-80^{\circ} \mathrm{C}$ until use. The concentration of VEGF was estimated using the ELISA system described above.

Cell culture and stimulation with semi-purified VEGF from the serum. Human aoertic endothelial cells (HAEC) were obtained from (BioWhittaker, Walkersville, Md., USA). The cells were cultured with MCDB131 medium (QIAGEN K.K., Tokyo, Japan) supplemented with $10 \%$ foetal bovine serum (FBS). When the cells reached subconfluence, were incubated with MCDB131 medium alone for $36 \mathrm{~h}$ prior to the examination. Cells were then incubated with MCDB131 medium containing $2 \%$ FBS in the presence or absence of $40 \%$ of serum semi-purified VEGF. Thereafter, cells were harvested and collected into $1.5 \mathrm{ml}$ centrifugation tubes.

RNA extraction and RT-PCR. Total RNA was isolated with RNeasy Mini Kit (QIAGEN K.K., Tokyo, Japan) according to the manufacturer's instructions. In order to evaluate MMP-3 and ETS-1 expression levels, 0.4 ug of total RNA was amplified by OneStep RT-PCR kit (QIAGEN K.K., Tokyo, Japan) using the following primers: MMP-3, 5' TTCTCCAGGATCTCTGAAGGAGAGG $3^{\prime}$ and 5' ATTTGGTGGGTACCACGA- 
GGACATC 3' (391 bp), ETS-1, 5' GGGTAGCGACTTCTCTTCTTGTTTG $3^{\prime}$ and 5' GTTAATGGAGTCAACCCAGC 3' (274 bp), $\alpha$-actin, $5^{\prime}$ TGGAATCCTGTGGCATCCATGAAAC $3^{\prime}$ and $5^{\prime}$ TAAAACGCAGCTCAGTAACAGTCCG 3'.

The RT-PCR products were run on $2.0 \%$ agarose gels and stained with ethidium bromide. The relative signal intensities of the PCR products were determined using a by luminescent image analyzer LAS-1000 (Fuji Photo Film, Tokyo, Japan). MMP- 3 and ETS-1 mRNA levels were normalized against $\alpha$ actin mRNA levels.

Statistical analysis. Statistical analyses were carried out using Statview J-4.5. Univariate relationships between anthropometric and serological variables and serum VEGF concentrations were assessed using Pearson's correlation analysis. To evaluate the independence of correlates of anthropometric and serological variables, stepwise regression analysis with forward selection procedures was used. A $p$ value of less than 0.05 was regarded as being statistically significant.

\section{Results}

Characteristics of subjects. The study included 38 obese subjects (10 males and 28 females); their ages varied from 22 to 66 years and their BMI values ranged 26.8 to $47.6 \mathrm{~kg} / \mathrm{m} 2$. The distribution of abdominal fat was assessed by computed tomography at umbilical levels. Visceral fat area varied from 41.0 to $236.2 \mathrm{~cm} 2$ and subcutaneous fat area ranged 209.2 to $797.7 \mathrm{~cm} 2$ (Table 1).

Correlation between serum VEGF concentration and visceral fat accumulation. Serum VEGF concentrations were significantly correlated with BMI $(r=0.433$, $p=0.007$ ) (Fig. 1). We used the Pearson correlation between visceral as well as subcutaneous fat areas and serum VEGF concentrations(Fig. 2A,B). Serum VEGF concentrations were positively related to visceral fat area $(\mathrm{r}=0.488, p=0.002)$ but not to subcutaneous fat area ( $\mathrm{r}=0.306, p=0.061)$ (Fig. 2A,B). These results indicate that the subjects with high intra-abdominal fat accumulation tend to have higher serum VEGF concentrations.

We then investigated the correlation between serum VEGF concentrations and various other serological

Table 1. Clinical characteristics of subjects

\begin{tabular}{lc}
\hline$n$ & 38 \\
\hline Age (years) & $39 \pm 12$ \\
Sex $($ Male/Female) & $10 / 28$ \\
BMI $\left(\mathrm{kg} / \mathrm{m}^{2}\right)$ & $33.8 \pm 5.1$ \\
Visceral fat area $\left(\mathrm{cm}^{2}\right)$ & $140.6 \pm 53.7$ \\
Subcutaneous fat area $\left(\mathrm{cm}^{2}\right)$ & $399.0 \pm 132.7$ \\
Fasting plasma glucose $(\mathrm{mmol} / \mathrm{l})$ & $5.27 \pm 0.49$ \\
Fasting insulin $(\mu \mathrm{U} / \mathrm{ml})$ & $11.7 \pm 5.3$ \\
Serum VEGF concentration $(\mathrm{pg} / \mathrm{ml})$ & $344.0 \pm 174.5$ \\
\hline
\end{tabular}

Data are means \pm SD. VEGF, vascular endothelial growth factor

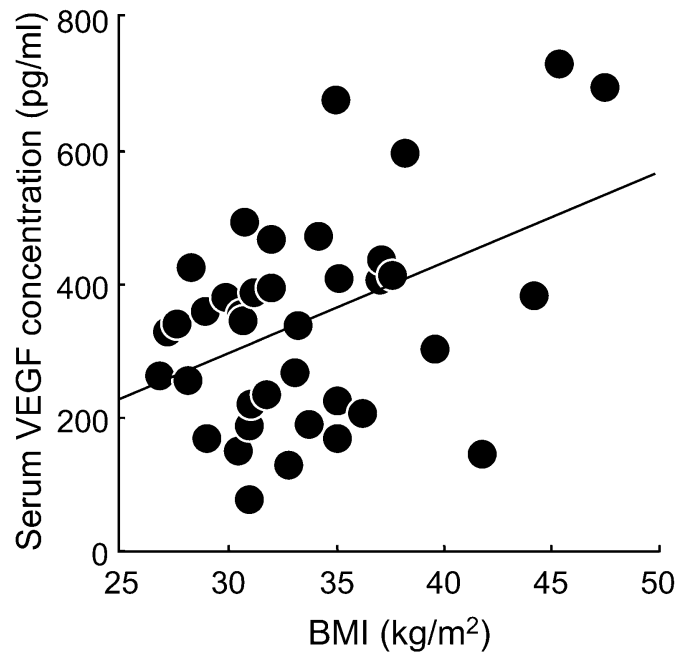

Fig. 1. Correlation between serum VEGF concentration and BMI in overweight and obese subjects. VEGF concentrations were significantly correlated with BMI $(r=0.433, p=0.007)$, $n=38$

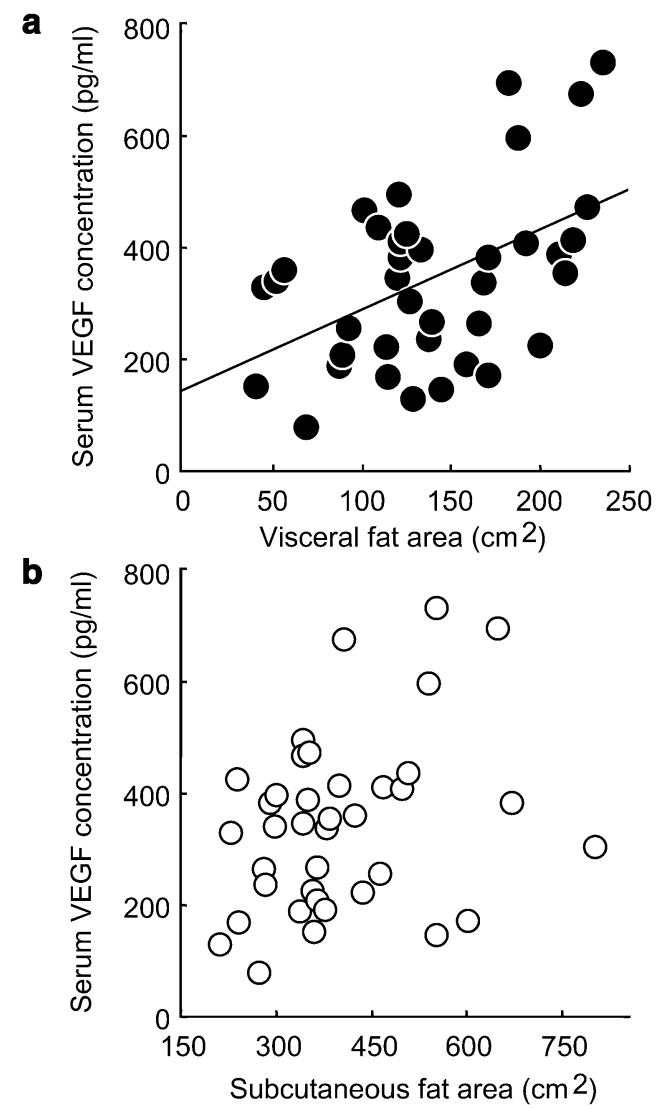

Fig. 2A, B. Correlation between serum VEGF concentration and visceral fat area in overweight and obese subjects. (A) Serum VEGF concentration vs visceral fat area. (B) serum VEGF concentration vs subcutaneous fat area. VEGF concentrations were positively related to visceral fat area $(\mathrm{r}=0.488, p=0.002)$ but not to subcutaneous fat area ( $\mathrm{r}=0.306, p=0.061), n=38$ 
Table 2. Correlation between serum VEGF and the variables associated with obesity

\begin{tabular}{lll}
\hline & $\mathrm{r}$ & $p$ value \\
\hline Age & 0.035 & 0.836 \\
BMI & 0.433 & 0.007 \\
Visceral fat area & 0.488 & 0.002 \\
Subcutaneous fat area & 0.306 & 0.061 \\
Serum TNF- $\alpha$ & 0.093 & 0.596 \\
Serum leptin & 0.117 & 0.603 \\
Fasting glucose & 0.139 & 0.407 \\
Fasting insulin & 0.346 & 0.033 \\
HOMA index & 0.321 & 0.049 \\
\hline
\end{tabular}

Data are means $\pm \mathrm{SD}$

Table 3. Stepwise regression analysis of selected variables on serum VEGF level

\begin{tabular}{llr}
\hline Independent variables & $\begin{array}{l}\text { Standardized regression } \\
\text { coefficient }\end{array}$ & $\mathrm{F}$ \\
\hline Visceral fat area & 0.488 & 11.247 \\
BMI & & 2.201 \\
Subcutaneous fat area & & 1.288 \\
Fasting insulin & & 0.926 \\
HOMA index & & 0.529 \\
\hline
\end{tabular}

The $\mathrm{F}$ value to enter was set at 4.0 at each step. VEGF, vascular endothelial growth factor. HOMA, homeostasis model assessment for insulin resistance

Table 4. Clinical characteristics of subjects who succeeded body weight reduction

\begin{tabular}{ll}
\hline$n$ & 8 \\
\hline Age (years) & $45 \pm 14$ \\
Sex (Male/Female) & $2 / 6$ \\
BMI $\left(\mathrm{kg} / \mathrm{m}^{2}\right)$ & $36.9 \pm 9.2$ \\
Visceral fat area $\left(\mathrm{cm}^{2}\right)$ & $166.6 \pm 42.2$ \\
Subcutaneous fat area $\left(\mathrm{cm}^{2}\right)$ & $422.1 \pm 188.1$ \\
Fasting plasma glucose $(\mathrm{mmol} / \mathrm{l})$ & $5.57 \pm 0.79$ \\
Fasting insulin $(\mu \mathrm{U} / \mathrm{ml})$ & $12.1 \pm 3.2$ \\
Serum VEGF concentration $(\mathrm{pg} / \mathrm{ml})$ & $409.9 \pm 167.6$ \\
\hline
\end{tabular}

Data are means $\pm \mathrm{SD}$

parameters associated with obesity (Table 2). Serum VEGF concentration had a positive correlation with fasting insulin as well as with HOMA index. The latter was calculated using the formula [fasting plasma glucose $(\mathrm{mmol} / \mathrm{l}) \times$ fasting insulin $(\mu \mathrm{U} / \mathrm{ml}) / 22.5]$. Stepwise regression analysis was also carried out using serum VEGF concentrations as the dependent variables and BMI, visceral and subcutaneous fat area, fasting insulin, and HOMA index as the independent variables. Stepwise regression analysis showed that visceral fat area was the most important determinant factor for serum VEGF in these variables (Table 3).
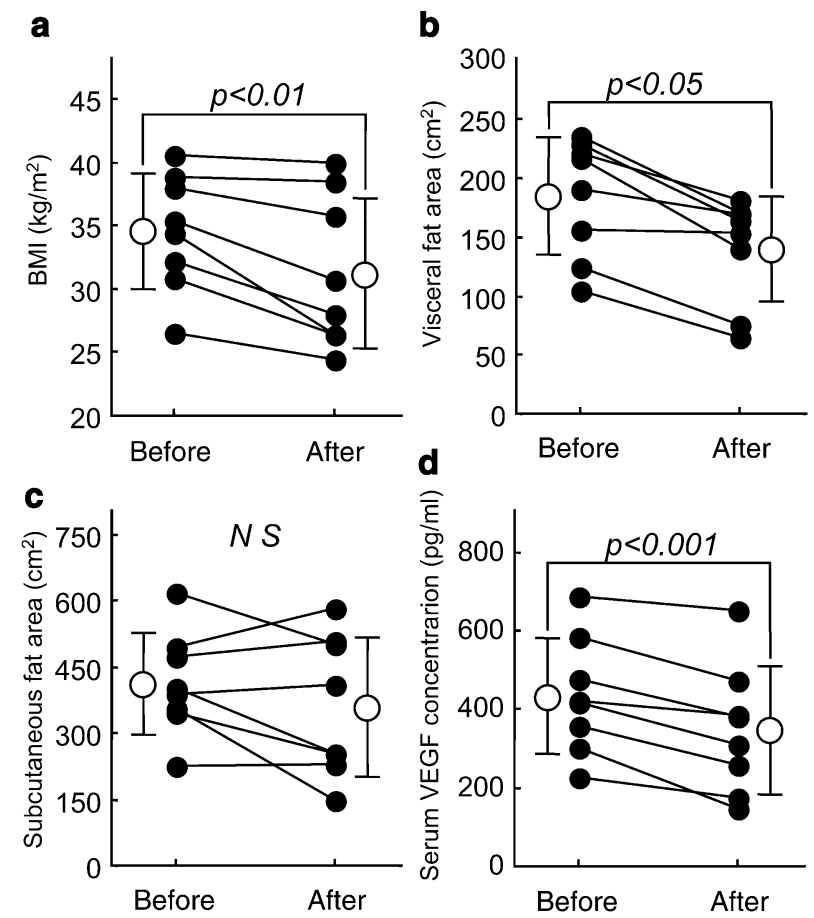

Fig. 3A-D. Changes of BMI, serum VEGF concentration, and visceral and subcutaneous fat area after body weight reduction. (A) Changes of BMI. (B) Changes of visceral fat area. (C) Changes of subcutaneous fat area. (D) Changes of serum VEGF concentration. Closed circle; individual parameters, open circle; mean value

Changes of serum VEGF after body weight reduction. Serum VEGF concentrations were measured at baseline and following weight-loss treatment. The effect of body weight reduction therapy on serum VEGF concentrations as well as subcutaneous and visceral fat areas was measured. The characteristics of the subjects treated with weight-loss therapy are shown in Table 4. In eight patients, with varying ages (24 to 61 years; BMI values ranging 30.6 to $56.8 \mathrm{~kg} / \mathrm{m} 2$ ), visceral fat area varied from 102.3 to $226.9 \mathrm{~cm}^{2}$ and subcutaneous fat area ranged from 224.6 to $793.6 \mathrm{~cm}^{2}$. Following weight-loss treatment, all subjects lost 4 to $6 \mathrm{~kg}$ of body weight relative to baseline (Fig. 3A). Visceral fat areas in all subjects had apparently decreased following body weight reduction while subcutaneous fat areas were not affected had not (Fig. 3B,C). Relative to baseline, post-therapy serum VEGF concentrations were decreased (Fig. 3D).

Biological activities of serum VEGF. To determine the biological activity of the circulating VEGF protein, partial purification of VEGF from the serum was done by using heparin sepharose beads. VEGF concentration after purification was estimated as $1032 \mathrm{pg} / \mathrm{ml}$ using ELISA kits. The purification efficiency was calculated as being 18.2 fold higher by using heparin sepharose (data not shown). We then investigated the effect of serum VEGF proteins on MMP-3 and ETS-1 


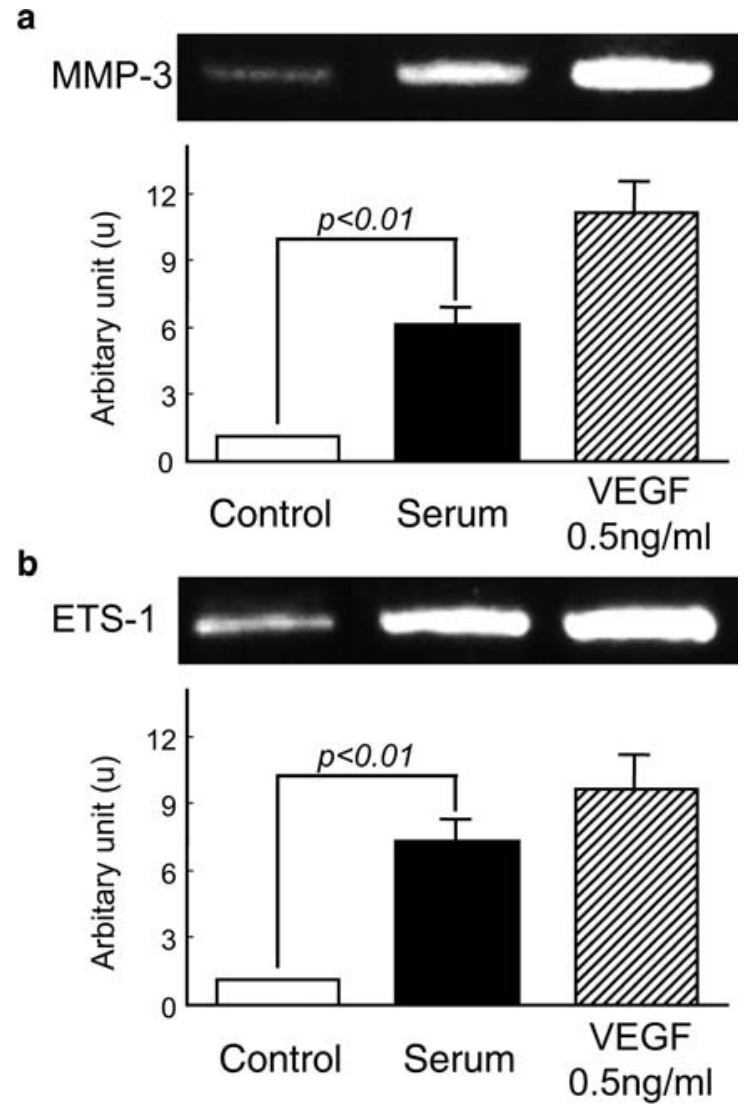

Fig. 4A, B. Effect of VEGF protein in serum on MMP-3 and ETS-1 expressions in human aortic endothelial cells. (A) Matrix metalloproteinase-3 (MMP-3). (B) E26 transformationspecific-1 (ETS-1). MMP-3 and ETS-1 expressions were enhanced 5.4-and 7.2-fold by incubation with partially purified VEGF from the serum, respectively. The data were represented by three independent experiments

expressions in HAEC. Exposure of cells to serum VEGF induced a 5.4-and 7.2-fold increase in MMP-3 and ETS-1 mRNA levels, respectively (Fig. 4A,B). The final concentration of VEGF proteins in the cell culture medium was measured as $413 \mathrm{pg} / \mathrm{ml}$ (data not shown).

\section{Discussion}

It has been reported that various cytokines such as TNF- $\alpha$, IL- 6 and PAI- 1 are secreted from the adipose tissues $[1,2,3,4,5]$. These cytokines are thought to play a key role in the development of obesity-associated pathologies such as atherosclerosis. The progressions of insulin resistance mediated by the circulating TNF- $\alpha$ and IL- 6 , and the coagulation disturbance with the increased level of PAI-1 are known to induce atherosclerosis $[4,10,18]$. An increase in the circulating level of these cytokines has also been shown to be related to the accumulation of intra-abdominal fat [11, $12,13]$.
VEGF is involved in normal and pathological vessel formation [28, 29]. VEGF mRNA expression as well as protein secretion are reported to be induced by adipocyte differentiation in 3T3-F442A cells, a murine pre-adipocyte cell line [21]. Moreover, secreted VEGF proteins induce an enhancement of sprouting as well as tube formation of vascular endothelial cells. Prior to this study, we clarified that human primary cultured adipocytes derived from secrete VEGF protein into the cell culture medium (145 pg protein in $1 \mathrm{ml}$ of the conditioned medium cultured with $1 \times 105$ cells of primary adipocytes). We have also shown the effect of VEGF protein on the enhancement of tube formation and the alteration of gene expressions in human endothelial cells.

The present study investigated in vivo the concentration of serum VEGF in obese subjects as well as verified the clear correlation between the circulating VEGF concentration and the severity of obesity. Circulating VEGF concentrations are shown to be correlated to visceral fat accumulation. Stepwise regression analysis showed that the visceral fat area is an independent but important factor for the determination of the serum VEGF concentration.

We also analyzed the effects of body weight reduction on the level of VEGF in serum. We randomly recruited eight subjects from the original pool of participants and divided these into two groups were matched for all clinical characteristics. The increased VEGF concentrations in the obese patients were reduced as the visceral fat area decreased after weight-loss treatment . These analyses showed that the VEGF secretion from adipose tissues, particularly from intra-abdominal adipose tissues, may regulate serum concentration of VEGF.

The present study also investigated the effect of partially purified serum VEGF on gene expression of MMP-3 and ETS-1 in endothelial cells. MMP-3 and ETS-1 gene expression has been reported to be induced by VEGF in endothelial cells [23]. The serum semi-purified VEGF showed the inducible activity for the gene expressions of MMP-3 and ETS- 1 at the similar level of recombinant VEGF. Growth factor induction of MMP-3 is thought to be involved in the pathogenesis of atherosclerosis as well as tumour invasion and metastasis [30, 31]. Matrix degradation enhances the ability of migration as well as tube formation in endothelial cells and could induce pathological neovascularization that is observed in atherosclerosis. These results suggest that the increased serum VEGF concentrations associated with intra-abdominal fat accumulation could influence vascular endothelial function.

Further investigations are required in order to elucidate the molecular mechanism of increased serum VEGF concentrations accompanied with intra-abdominal fat accumulation as well as its pathological significance in the acceleration of vascular disorders associated with obesity. 
Acknowledgements. These studies were supported by grants from the Japanese Ministry of Education, Science, Sports and Culture. We thank to Dr. Cosette Choeiri for critical reading.

\section{References}

1. MacDougald OA, Hwang CS, Fan H, Lane MD (1995) Regulation of the obese gene product (Leptin) in white adipose tissue and 3T3 adipocytes. Proc Natl Acad Sci USA 92:9034-9037

2. Caro JF, Sinha MK, Kolaczynski JW, Zhang PL, Considine RV (1996) Leptin: the tale of an obesity gene. Diabetes 45:1455-1462

3. Hotamisligil GS, Shargill NS, Spiegelman BM (1993) Adipose expression of tumor necrosis factor-alpha: direct role in obesity-linked insulin resistance. Science 259:87-91

4. Shimomura I, Funahashi T, Takahashi M et al. (1996) Enhanced expression of PAI-1 in visceral fat: possible contributor to vascular disease in obesity. Nat Med 2:800-803

5. Mohamed-Ali V, Goodrick S, Rawesh A et al. (1997) Subcutaneous adipose tissue releases interleukin-6, but not tumor necrosis factor-alpha, in vivo. J Clin Endocr Metab 82:4196-4200

6. Bastard JP, Jardel C, Bruckert E et al. (2000) Elevated levels of interleukin 6 are reduced in serum and subcutaneous adipose tissue of obese women after weight loss. J Clin Endocrinol Metab 85:3338-3342

7. Maffei M, Halaas J, Ravussin E et al. (1995) Leptin levels in human and rodent: measurement of plasma leptin and ob RNA in obese and weight-reduced subjects. Nat Med $1: 1155-1161$

8. Considine RV, Sinha MK, Heiman ML et al. (1996) Serum immunoreactive-leptin concentrations in normal-weight and obese humans. N Engl J Med 334:292-295

9. Kern PA, Saghizadeh M, Ong JM, Bosch RJ, Deem R, Simsolo RB (1995) The expression of tumor necrosis factor in human adipose tissue. Regulation by obesity, weight loss, and relationship to lipoprotein lipase. J Clin Invest 95:2111-2119

10. Hotamisligil GS, Arner P, Caro JF, Atkinson RL, Spiegelman BM (1995) Increased adipose tissue expression of tumor necrosis factor-a in human obesity and insulin resistance. J Clin Invest 95:2409-2415

11. Dandona P, Weinstock R, Thusu K, Abdel-Rahman E, Aljada A, Wadden T (1998) Tumor necrosis factor-alpha in sera of obese patients: fall with weight loss. J Clin Endocrinol Metab 83:2907-2910

12. Cella F, Adami GF, Giordano G, Cordera R (1999) Effects of dietary restriction on serum leptin concentration in obese women. Int J Obes Relat Metab Disord 23:494-497

13. Wadden TA, Considine RV, Foster GD, Anderson DA, Sarwer DB, Caro JS (1998) Short- and long-term changes in serum leptin dieting obese women: effects of caloric restriction and weight loss. J Clin Endocrinol Metab 83: 214-218

14. Kissebah AH, Vydelingum N, Murray R (1982) Relation of body fat distribution to metabolic complications of obesity. J Clin Endocrinol Metab 54:254-260

15. Hodge AM, Dowse GK, Zimmet PZ (1993) Association of body mass index and waist-hip circumference ratio with cardiovascular disease risk factors in Micronesian Nauruans. Int J Obes Relat Metab Disord 17:399-407
16. Tokunaga K, Matsuzawa Y, Ishikawa K (1983) A novel technique for the determination of body fat by computed tomography. Int J Obes 7:437-745

17. Suzuki R, Watanabe S, Hirai Y et al. (1993) Abdominal wall fat index, estimated by ultrasonography, for assessment of the ratio of visceral fat to subcutaneous fat in the abdomen. Am J Med 95:309-314

18. Matsuzawa Y, Funahashi T, Nakamura T (2002) Molecular mechanism of vascular disease in metabolic syndrome X. J Diabetes Complications 16:17-18

19. Shibasaki M, Takahashi K, Itou T et al. (2002) Alterations of insulin sensitivity by the implantation of 3T3-L1 cells in nude mice. A role for TNF-alpha? Diabetologia 45:518526

20. Neufeld, G, Cohen T, Gengrinovitch S, Poltrak Z (1999) Vascular endothelial growth factor (VEGF) and its receptors. FASEB J 13:9-22

21. Claffey KP, Wilkison WO, Spiegelman BM (1992) Vascular endothelial growth factor: regulation by cell differentiation and activated second messenger pathways. J Biol Chem 267:16317-16322

22. Blann AD, Belgore FM, McCollum CN, Silverman S, Lip PL, Lip GY (2002) Vascular endothelial growth factor and its receptor, Flt-1, in the plasma of patients with coronary or peripheral atherosclerosis, or Type II diabetes. Clin Sci (Lond) 102:187-194

23. Sato Y, Abe M, Tanaka K et al. (2000) Signal transduction and transcriptional regulation of angiogenesis. Adv Exp Med Biol 476:109-115

24. Kobayashi J, Tashiro J, Murano S, Morisaki N, Saito Y. (1998) Lipoprotein lipase mass and activity in post-heparin plasma from subjects with intra-abdominal visceral fat accumulation. Clin Endocrinol 48:515-520

25. Matthews DR, Hosker JP, Rudenski AS, Naylor BA, Treacher DF, Turner RC (1985) Homeostasis model assessment: insulin resistance and beta-cell function from fasting plasma glucose and insulin concentrations in man. Diabetologia 28:412-419

26. Emoto M, Nishizawa Y, Maekawa K et al. (1999) Homeostasis model assessment as a clinical index of insulin resistance in type 2 diabetic patients treated with sulfonylureas. Diabetes Care 22:818-822

27. Bonora E, Targher G, Alberiche M et al. (2000) Homeostasis model assessment closely mirrors the glucose clamp technique in the assessment of insulin sensitivity: studies in subjects with various degrees of glucose tolerance and insulin sensitivity. Diabetes Care 23:57-63

28. Stephan CC, Brock TA (1996) Vascular endothelial growth factor, a multifunctional polypeptide. PR Health Sci J 15:169-178

29. Ferrara N (2002) Links Role of vascular endothelial growth factor in physiologic and pathologic angiogenesis: therapeutic implications. Semin Oncol 29:10-14

30. Sreenath T, Matrisian LM, Stetler-Stevenson W, GattoniCelli S, Pozzatti RO (1992) Expression of matrix metalloproteinase genes in transformed rat cell lines of high and low metastatic potential. Cancer Res 52:4942-4947

31. Kanaki T, Bujo H, Mori S et al. (2002) Functional analysis of aortic endothelial cells expressing mutant PDGF receptors with respect to expression of matrix metalloproteinase3. Biochem Biophys Res Commun 2002 294:231-237 